ANA LUCIA IKENAGA

\title{
A ATRIBUIÇÃO DE NOME COMO MODO DE EXPLORAÇÃO DE BENS PÚBLICOS
}

FACULDADE DE DIREITO DA UNIVERSIDADE DE SÃO PAULO SÃO PAULO

2012 
ANA LUCIA IKENAGA

\section{A ATRIBUIÇÃO DE NOME COMO MODO DE EXPLORAÇÃO DE BENS PÚBLICOS}

Dissertação de mestrado apresentada ao Departamento de Direito do Estado da Faculdade de Direito da Universidade de São Paulo para obtenção do título de Mestre em Direito.

Orientação: Prof. Dr. Floriano de Azevedo Marques Neto

FACULDADE DE DIREITO DA UNIVERSIDADE DE SÃO PAULO SÃO PAULO 


\section{RESUMO}

O presente trabalho teve como objetivo realizar uma avaliação quanto à possibilidade de serem explorados bens públicos intangíveis no Direito brasileiro. O tema foi abordado especificamente quanto à "atribuição de nome", como modo de exploração de bens públicos. $\mathrm{Na}$ experiência estrangeira, verifica-se a existência dos naming rights. A atribuição de nome é um instituto que pode ser desenvolvido no Brasil, inspirado nos naming rights, mas observadas as peculiaridades do ordenamento jurídico brasileiro. A atribuição de nome pode ser usada tanto no âmbito privado quanto no aspecto público. Para delinear o instituto é necessário distinguir a atribuição de nome de outros institutos que possam demonstrar aparente aproximação. A atribuição de nome não se confunde com nomeação honorífica, doação com encargo, contratos para conservação de bens públicos ou locação. A atribuição de nome demonstra ser um meio viável para exploração de bens públicos, mas para o seu sucesso faz-se necessário estabelecer limites a esse instituto, evitando-se repetir erros que já foram verificados na experiência estrangeira. A cessão da atribuição de nome deve ser pautada pela análise de critérios de conveniência e pelo estabelecimento de marcos legais em conformidade com o ordenamento jurídico brasileiro. 


\section{RÉSUMÉ}

Cette étude a pour but l'évaluation concernant la possibilité d'exploitation de biens publics intangibles du Droit brésilien. Le thème fut particulièrement envisagé par rapport à "l'attribution de nom" comme une manière d'exploiter les biens publics. A l'étranger, il y a les naming rights. L'attribution de nom est un ensemble de règles juridiques qui peut être développée au Brésil, inspirée des naming rights, à condition que les particularités de l'ordonnancement juridique brésilien soient respectées. L'attribution de nom peut être utilisée dans le domaine privé ou public. Pour définir l'ensemble de règles juridiques, il faut distinguer l'attribution de nom d'autres ensembles qui puissent indiquer une apparente approximation. L'attribution de nom ne peut pas être confondue avec la nomination honorable, la donation avec charge, les contrats pour le maintien de biens publics ou la location. L'attribution de nom paraît un moyen viable pour l'exploitation de biens publics. Toutefois, pour sa réussite, il faut établir de limites afin que des erreurs commises à l'étranger ne se passent pas au Brésil. La cession de l'attribution de nom doit être basée sur l'analyse de critères d'intérêt général et sur l'établissement de repères de la loi suivant l'ordonnancement juridique brésilien. 


\section{INTRODUÇÃO}

O Direito Administrativo brasileiro talvez seja um dos ramos de estudo jurídico que mais tenha sofrido transformações nas últimas décadas porque tenta conciliar a satisfação das necessidades coletivas com desenvolvimento econômico. Tratase do caráter interdisciplinar próprio desse ramo de estudo. Ao mesmo tempo em que se espera que as mudanças econômicas validem a atuação estatal cada vez menor, se vê a necessidade de proporcionar um atendimento mínimo ${ }^{1}$ a um número cada vez maior de pessoas.

Ainda que estatisticamente os brasileiros estejam gerando cada vez menos filhos, isso não ocorre na mesma proporção em famílias de menor poder aquisitivo quanto se passa nas famílias de classes sociais mais elevadas. Os ganhos familiares continuam, desse modo, sendo divididos entre vários integrantes. Entre os mais pobres não se vê famílias tão numerosas como as que existiam há sessenta anos, mas ainda há demanda para a atuação estatal face a manutenção da pobreza e das desigualdades sociais. Ademais, se a expectativa de vida é ampliada face ao desenvolvimento econômico, isso gera também a exigência de obter uma atuação estatal diferenciada do que existia no século passado, já que as necessidades mínimas da população não diminuem.

Esse mínimo existencial ${ }^{2}$ se relaciona notadamente com as necessidades mais fundamentais do ser humano: assistência social, saúde e educação ${ }^{3}$.

Ano após ano visualiza-se o Estado superar records de arrecadação de impostos, justamente porque o país passa por transformações econômicas que têm se mostrado favoráveis. Contudo, essas transformações mostram-se limitadas para gerar riquezas e atrair investimentos, como se gostaria. Aliado a isso, os recursos públicos são

\footnotetext{
1 Esse mínimo se relaciona com a proteção dos direitos fundamentais que consistem no "conjunto institucionalizado de direitos e garantias do ser humano, que tem por finalidade básica o respeito à sua dignidade, por meio de sua proteção contra o arbítrio do poder estatal e o estabelecimento de condições mínimas de vida e desenvolvimento da personalidade humana." (MORAES, Alexandre de. Constituição do Brasil interpretada e legislação constitucional, p. 162).

${ }^{2}$ Sobre o aspecto patrimonial consulte-se Luiz Edson FACHIN (Estatuto jurídico do patrimônio mínimo).

${ }^{3}$ A tutela do patrimônio mínimo comporta o acesso à educação, saúde e assistência social como valores merecedores de proteção para a dignidade humana.
} 
insuficientes para servir à redução das desigualdades. $\mathrm{O}$ enfrentamento da marginalização impõe que o Estado atue tanto no âmbito social, promovendo assistência social e saúde, quanto na educação, cuja demanda - que ocorre em todos os níveis - é também crescente em razão desse cenário de desenvolvimento econômico. ${ }^{4}$

Tudo isso determina uma adaptação estatal para se adequar às necessidades e superar as deficiências do sistema. Não se pode fechar os olhos para a realidade existente. Por outro lado, as novidades eventualmente surgidas nas instituições consagradas devem ser vistas com extrema cautela. Não é possível deslumbrar-se com os aspectos positivos e ignorar os pontos negativos como se o que é inovador fosse uma solução pronta e acabada para todos os problemas estatais. Deve-se buscar instrumentos para permitir uma adaptação da nova realidade que vai surgindo, marcada por deficiências estatais e carências humanas, ao dever de satisfação das necessidades mínimas coletivas.

Nesse cenário, identifica-se no plano internacional o instituto dos naming rights. Há predomínio de aplicação no âmbito privado, com uso mais corrente em estádios esportivos, mas não somente neles. Verifica-se sua aplicação também em escolas, hospitais e infraestrutura de serviço público de transporte coletivo. Afigura-se um instrumento relevante para obtenção de recursos, o que poderia ser bastante interessante se houvesse a viabilidade de adaptar a ideia geral, a essência, desse instituto para a realidade pública brasileira.

Para tanto, é necessário além de verificar os aspectos positivos, apontar as limitações ao seu uso no ordenamento jurídico brasileiro.

Com essa proposta estabeleceu-se como objetivo geral do presente estudo realizar uma avaliação quanto à possibilidade e eventuais limites de serem explorados bens públicos intangíveis no Direito brasileiro, especificamente a atribuição de nome como modo de exploração de bens públicos, visando à maior eficiência e ao aproveitamento desses bens.

\footnotetext{
${ }^{4}$ Tanto o fenômeno da industrialização e a concentração de pessoas nas áreas urbanas, quanto a era tecnológica impõem que os candidatos a postos de trabalho estejam preparados para novas realidades.
} 
Os objetivos específicos do estudo, parcialmente alterados após o exame de qualificação, consistiram em:

(i) Examinar a exploração econômica de bens públicos;

(ii) Identificar o uso dos naming rights na experiência norte-americana;

(iii) Apontar a perspectiva de uso no âmbito do direito brasileiro;

(iv) Traçar um delineamento do que seria a atribuição de nome, realizando uma breve comparação com outros institutos conhecidos e usados no direito brasileiro;

(v) Verificar se esses ativos intangíveis representam um valor significativo que imponha o dever de explorá-los face à escassez de recursos públicos;

(vi) Investigar se a exploração desses ativos poderia esbarrar nas restrições impostas pelo regime jurídico à exploração de bens públicos;

(vii) Realizar uma avaliação das necessidades de adequação para o uso da atribuição de nome no direito público brasileiro.

Duas hipóteses foram formuladas para fundamentar a resposta afirmativa à questão principal: a atribuição de nome de bens públicos pode ser explorada no Direito brasileiro?

(i) Os ativos intangíveis de atribuição de nome devem ser explorados como modo de dar maior aproveitamento aos bens públicos.

Considerando que:

(a) as crescentes necessidades coletivas demandam investimentos públicos nas mais diversas áreas: saúde, educação, infraestrutura, segurança etc.

(b) a atribuição de nome é um ativo economicamente importante; 
(c) a atribuição de nome consiste em um ativo ainda pouco utilizado mesmo no âmbito privado;

(d) a cessão da atribuição de nome seria realizada de modo oneroso;

(e) a atribuição de nome seria um modo de dar maior eficiência possível à exploração dos bens públicos;

A Administração pública tem o dever, em certos casos, de conferir a máxima exploração dos bens públicos em um cenário econômico e social como o que se apresenta.

(ii) A utilização privativa da atribuição de nome de um bem público por um particular é compatível com o ordenamento jurídico brasileiro.

Considerando que:

(a) os bens públicos comportam múltiplas utilizações;

(b) a cessão da atribuição de nome consiste em um uso secundário de um bem público;

(c) o uso secundário não desnatura o bem público;

(d) as restrições impostas pelo regime jurídico não seriam capazes de impedir a exploração secundária dos bens públicos pela atribuição

(e) na atribuição de nome devem-se observar as regras vigentes quanto à escolha do particular.

A cessão da atribuição de nome poderia ser realizada no Brasil, eis que a exploração dos ativos intangíveis não encontra obstáculo na doutrina dos bens públicos, desde que se observem determinados critérios políticos e jurídicos. 
Diante disso, o trabalho foi estruturado em quatro capítulos, que tratam sobre exploração econômica de bens públicos, naming rights, atribuição de nome no direito brasileiro, atribuição de nome e bens públicos.

No primeiro capítulo é realizada uma exposição sumária do cenário de carências sociais, passando pela formulação de políticas públicas e pela necessidade de haver recursos públicos para prestar esse atendimento.

No segundo capítulo apresenta-se o panorama do instituto dos naming rights, utilizados há mais tempo nos Estados Unidos. Há uma tentativa de se conceituar o instituto e apresentar sua natureza. Expõe-se os riscos e os limites decorrentes da utilização desse modo de exploração econômica.

O terceiro capítulo tem como principal objetivo estabelecer distinções entre a atribuição de nome e outros institutos conhecidos do ordenamento jurídico pátrio, passando pela perspectiva de utilização dela. Em seguida, outras questões relacionadas ao tema são tratadas com o fim de traçar algumas diretrizes para o uso do instituto.

No último capítulo aborda-se especificamente a cessão da atribuição de nome de bens públicos. No entanto, face à inexistência de estudos anteriores sobre o tema há a necessidade de se criar uma tentativa de sistematização de alguns critérios, que podem ser estabelecidos para evitar a ocorrência de problemas que já surgiram na experiência estrangeira.

Se por um lado, o grande desafio do tema escolhido decorre da quase inexistência de tratamento doutrinário do instituto no âmbito jurídico; por outro, isso permite uma grande flexibilidade ao poder criativo do ser humano, a partir da essência dos naming rights estrangeiros.

Na prática, o que se verifica é que, conforme José Eduardo FARIA anota que:

o Estado já não consegue mais regular a sociedade e gerir a economia exclusivamente por meio de seus instrumentos jurídicos tradicionais e de suas soluções padronizadoras, 
concebidas em termos rigidamente dicotômicos ou binários (ex.: constitucional vs. inconstitucional, legal vs. ilegal, lícito vs. olícito, facultativo vs. obrigatório, permitido vs. proibido, público vs. privado, estatal vs. social, individual vs. coletivo, justiça comutativa vs. justiça distributiva, justiça formal vs. justiça material etc.). ${ }^{5}$

Deve-se, por isso, despir-se de uma rejeição inicial ao instituto decorrente de conceitos anteriores e contrários à mercantilização (imagem negativa que pode ser associada ao instituto, mas que dele não é parte indissociável) para permitir-se conhecer, analisar, ponderar, até mesmo criticar, para então buscar soluções para os problemas surgidos, enfrentando dessa maneira os desafios existentes.

Em outras palavras, a pretensão deste trabalho é modesta: não há respostas prontas ou soluções acabadas. Quer-se, tão somente, sugerir a ideia que pode inspirar a acolhimento do instituto, de modo a viabilizar a implementação da atribuição de nome para determinados bens públicos e ampliar, desse modo, os recursos públicos para serem destinados ao atendimento das necessidades coletivas. A viabilidade e a extensão dessa produção deve passar por um amplo debate, do qual este trabalho se traduz apenas na tentativa de começar.

\footnotetext{
${ }^{5}$ FARIA, José Eduardo. Direito e conjuntura, p. 52/53.
} 


\section{CONSIDERAÇÕES FINAIS}

A presente dissertação teve como objetivo realizar uma avaliação quanto à possibilidade e eventuais limites de se adotar a atribuição de nome como um modo de exploração de bens públicos.

A atribuição de nome é instituto compatível com a doutrina que sustenta a possibilidade de ser realizada a máxima exploração econômica de bens públicos. Como um bem público pode comportar múltiplos usos, em um cenário de escassez, as potencialidades econômicas devem, sempre que possível, ser aproveitadas. Quando a finalidade não for um interesse coletivo especifico, a racionalidade dessa exploração deve reverter em prol da coletividade fazendo ingressar recursos privados nos cofres públicos.

Se por um lado a atribuição de nome faculta ao particular apropriarse da referência de um bem público, por outro, ela retrata também uma apropriação pública de riquezas privadas, já que o ente público beneficia-se com essa junção entre uma marca privada e a utilidade. Serão tanto maiores os benefícios para os cofres públicos quanto mais interessantes forem os potenciais investidores privados, que detiverem marcas sólidas, de renome e que pretendam vê-las associadas a bens públicos.

Como exposto, é necessário tanto realizar a autorização legislativa quanto a regulamentação de seu uso, notadamente com relação aos critérios de seleção do particular, especialmente tomando em vista a disciplina do instituto de maneira uniforme para os demais entes da federação.

No tocante ao modo de eliminar nomes indesejáveis, talvez fosse possível realizar uma nova modelagem licitatória que pudesse pontuar as escolhas, com o mínimo de subjetividade possível, deixando o critério preço com um peso menor (mas não menos relevante) na decisão com relação à proposta mais vantajosa para a administração. 
Dois aspectos vão merecer um esforço a mais por parte do legislador que tiver simpatia com relação à temática de atribuição de nome para bens públicos. Como a experiência norte-americana apontou, em muitos casos lá não houve a adequada publicidade quanto aos diversos aspectos da contratação. A ausência de regras dessa natureza dificulta o controle público e deixa a impressão de uma ausência de legitimidade democrática nas escolhas, já que não se sabe como exatamente foram realizadas e nem o que é feito do dinheiro recebido.

O primeiro item relaciona-se com a legitimação democrática da decisão. Embora os parlamentares sejam os representantes do povo, é notório que a maior parte da população pouco se recorda dos nomes que figuravam na lista de candidatos da última eleição e especialmente, quais foram os escolhidos por cada pessoa. Em vista disso, é natural que muitos não se sintam representados quando são tomadas decisões que causem grande repercussão na vida das pessoas.

Para a tomada dessas decisões, em um primeiro momento, faz-se necessário realizar avaliações econômicas da estimativa das receitas que podem ser auferidas concretamente. Em um segundo momento, é interessante permitir a ampla participação da população na tomada de decisão, o que se faz por meio de consultas públicas. Nessa situação, a Administração Pública poderá adotar condutas orientadas a evitar problemas que possam ter sido pontuados previamente pelos interessados. A consulta pública pode fornecer elementos importantes para a conformação do instituto.

Por fim, segundo dispõe a Constituição Federal, a participação democrática pode ser facultada aos interessados por meio da convocação de plebiscito (consulta prévia) e de referendo (posterior à elaboração da lei). E para evitar a ampliação desses custos, pode-se fazê-lo juntamente com as eleições que levam os brasileiros às urnas a cada dois anos. Ou seja, dispõem-se dos instrumentos e dos recursos para permitir a oitiva da população, basta vontade política em fazê-lo.

O segundo item de destaque consiste no destino a ser dado aos recursos públicos. Conforme o vulto deles poder-se-ia considerar a instituição de uma 
fundação pública com o objetivo de gerir o dinheiro e aplicá-lo em finalidades específicas, preferencialmente ligadas ao bem público explorado.

Tal como ocorre no estrangeiro, o interessante é direcionar os recursos para o próprio objeto vinculado à atribuição de nome..$^{6-7}$

O estatuto de Nevada dispõe que "o dinheiro mantido no fundo somente pode ser utilizado para pagar despesas diretamente relacionadas com os custos do hospital público para a construção, melhoria, manutenção ou programas". 8

Em tese até se poderia admitir que os recursos arrecadados fossem usados não só para a manutenção, conservação e melhoria do bem público como também para quitar débitos realizados com a própria construção da obra pública ${ }^{9}$, aliás, a concessão de uso poderia ter como uma das obrigações a construção da obra que será objeto de cessão de atribuição de nome, sem a necessidade de haver previamente recursos públicos para isso.

Enfim, a exploração da atribuição de nome não só é um instituto compatível com os bens públicos, como pode e deve ser realizada quando for conveniente para gerar recursos públicos para serem destinados às finalidades coletivas. $\mathrm{O}$ atendimento a essas necessidades é uma tarefa que incumbe ao Estado e a que ele não pode se desobrigar nem mesmo sob a alegação de existir limitações orçamentárias enquanto houver bens que possam ser economicamente explorados.

\footnotetext{
${ }^{6}$ Conn. Gen. Stat. $\$ 32-602$ (2011).

${ }^{7}$ Nev. Rev. Stat. Ann. § 244.30701 (2011).

${ }^{8}$ Nev. Rev. Stat. Ann. $\$ 450.810$ (2011). Tradução livre.

${ }^{9}$ Assim se passa em Porto Rico conf. 23 L.P.R.A. § 228e (2008).
} 


\section{REFERÊNCIAS BIBLIOGRÁFICAS}

Documentos oficiais

23 L.P.R.A. § 228(2008). Disponível em LexisNexis. Acesso em 01.07.2011.

23 L.P.R.A. § 228b(2008). Disponível em LexisNexis. Acesso em 01.07.2011.

23 L.P.R.A. $§ 228 f(2008)$. Disponível em LexisNexis. Acesso em 05.07.2011.

70 ILCS 210/5.7(2011). Disponível em LexisNexis. Acesso em 22.06.2011.

70 ILCS 210/5.7(2011). Disponível em LexisNexis. Acesso em 23.06.2011.

Conn. Gen. Stat. § 13b-23a(2011). Disponível em LexisNexis. Acesso em 22.06.2011.

Conn. Gen. Stat. § 32-656(2011). Disponível em LexisNexis. Acesso em 22.06.2011.

Nev. Rev. Stat. Ann. § 450.810(2011). Disponível em LexisNexis. Acesso em 30.06.2011.

Statement of Motives. Fifteenth legislature - Fifth ordinary session, nr. 170, Senate Bill 1716, 2007 PR ALS 170; 2007 PR LAWS 170; 2007 PR ACT 170; 2007 PR S.B. 1716. Acesso em 06.07.2011. 
Livros e artigos

ALESSI, Renato. Sistema Istituzionale del diritto amministrativo italiano. Milano: Giuffrè, 1953.

ALTBACH, Philip G. What's in a Name? Academe, Vol. 92, No. 1 (Jan. - Fev./2006), p. 48-49, publicado por American Association of University Professors. Disponível em Jstor. Acesso em 02.09.2010.

AMARAL, Francisco. Direito civil: introdução. 7. ed. rev., mod., aumentada. Rio de Janeiro: Renovar, 2008.

ASSIS, Araken. Manual de execução. 9. ed. rev., atual. e ampl. da 8. ed. do livro Manual do processo de execução. São Paulo: Revista dos Tribunais, 2004.

ASTER, Charles E.; TILLINGHAST III, Edward H. New play book page: stadium naming rights. New York Law Journal , 27.08.2001, v. 226, ed. 40, p. 7.

AUBY, Jean-Marie et al. Droit administratif des biens. 5. ed., Paris: Dalloz, 2008.

BACELlAR FILHO, Romeu Felipe. Direito administrativo. 2. ed., São Paulo: Saraiva, 2005

BANDEIRA DE MELLO, Celso Antônio. Curso de direito administrativo. 21. ed., São Paulo: Malheiros, 2006.

Elementos de direito administrativo. 3. ed. rev., ampl. e atual., São Paulo: Malheiros, 1992.

BARROS MONTEIRO, Washington de, Curso de direito civil. 39. ed., atualiz. por Ana Cristina de Barros Monteiro França Pinto, São Paulo: Saraiva, 2003.

BARTOW, Ann. Distributive justice and intellectual property: trademarks of privilege: Naming rights and the physical public domain, 40 U.C. Davis L. Rev. 919-970, mar./2007. 
BEAUREGARD-BERTHIER, Odile de David. Droit administratif des biens. 5. ed. Paris: Gualino, 2007.

BLECHER, Shari M.; LIEBERMAN, Stuart, Ensuring stormwater compliance, New Jersey Law Journal, 28.01.2008, s./p. Disponível em LegalTrac. Acesso em 03.09. 2010.

BLOCHER, Joseph. School naming rights and the first amendment's perfect storm, publicado em The Georgetown Law Journal, vol. 96:1, Disponível em HeinOnline - 96 Geo. L.J. 1 2007-2008. Acesso em 03.09.2010.

Selling the name on the schoolhouse gate: the first amendment and the sale of public school naming rights. Disponível na internet em http://scholarship.law.duke.edu/faculty_scholarship/1960/. Acesso em 25.08.2010.

BURTON, Terry. Naming rights: legacy gifts \& corporate money. [s/1]: Wiley, 2008.

CANOTILHO, Joaquim José Gomes. Direito constitucional e teoria da Constituição. 7. ed., Coimbra: Almedina, 2003.

CARNEIRO, Athos Gusmão. Intervenção de terceiros. 13. ed., São Paulo: Saraiva, 2001.

CARVALHO FILHO, José dos Santos. Manual de direito administrativo. 21. ed., Rio de Janeiro: Lumen Juris, 2009.

CAVALCANTI, Themistocles. Curso de direito administrativo. 6. ed., Rio de Janeiro-São Paulo: Freitas Bastos, 1961.

CHAPUS, René. Droit administratif général. 15. ed., Paris: Montchrestien, 2001. v. 2.

CITADINI, Antonio Roque. A economicidade nos gastos públicos, publicado no jornal $O$ Estado de São Paulo, de 30.04.1989, p. 40. Disponível em http://www.citadini.com.br/artigos/oesp8904.htm . Acesso em 19.07.2011.

COKER, Margaret. Dubai Pulls Out the Stops-for Naming. Wall Street Journal - Eastern Edition; 8/8/2008, vol. 252, ed. 33, p. 3. Disponível em Ebscohost. Acesso em 22.09.2010 
COMPARATO, Fábio Konder. Ensaio sobre o juízo de constitucionalidade de políticas públicas. Revista Interesse Público, ano 4, n 16, out./dez 2002, Porto Alegre: Notadez, p. 49-63.

CONN, Richard S., Department: practice tips: caveat donor for charitable giving, publicado em Los Angeles Lawyer 33 - Los Angeles Bar Association, Julho-Agosto, 2010.

DAL BOSCO, Maria Goretti. Discricionariedade em políticas públicas. Curitiba: Juruá, 2007.

DI PIETRO, Maria Sylvia Zanella. Uso privativo de bem público por particular. 2. ed., São Paulo: Atlas, 2010.

. Direito administrativo. 20. ed., São Paulo: Atlas, 2007.

. Parecer 2 em Parcerias na administração pública. 5. ed., São Paulo: Atlas, 2006.

. Função social da propriedade pública. Direito público, coord. por Luiz Guilherme

Costa Wagner Junior. Belo Horizonte: Del Rey, 2004, p. 561-572.

_. Discricionariedade administrativa na Constituição de 1988. São Paulo: Atlas, 1991.

A gestão jurídica do patrimônio imobiliário do Poder Público. Cadernos Fundap. São Paulo, ano 9, nº 17, p. 55-66, dez./1989.

DINIZ, Maria Helena. Código civil anotado. 8. ed. São Paulo: Saraiva, 2002.

DUGUIT, León. Las transformaciones del derecho: público y privado. Buenos Aires: Heliasta, s/d.

DUPUIS et al. Droit administratif. 11. ed., Paris: Dalloz, 2009.

DWORKIN, Ronald. Levando os direitos a sério. São Paulo: Martins Fontes, 2002.

ESPÍNOLA, Eduardo. Dos contratos nominados no direito civil brasileiro. 2. ed., Rio de Janeiro: Conquista, 1956. 
FACHIN, Luiz Edson. Estatuto jurídico do patrimônio mínimo. 2. ed. atualiz., Rio de Janeiro-SãoPaulo-Recife: Renovar, 2006.

FARIA, José Eduardo. Direito e conjuntura. São Paulo: Saraiva, 2008, p. 52/53.

FIUZA, César. Direito civil: curso completo. 9. ed., rev., atual. e ampl., Belo Horizonte: Del Rey, 2006.

FRANÇA, R. Limongi. Instituições de direito civil. 2. ed. São Paulo: Saraiva, 1991.

FRANCO SOBRINHO, Manoel de Oliveira. O princípio constitucional da moralidade administrativa. 2. ed., Curitiba: Genesis, 1993, p. 159.

GAUDEMET, Yves. Traité de droit administratif. 13. ed., L.G.D.J.: Paris, v. 2, 2008.

GIDRON, Benjamin et al. Government and the Third Sector: in comparative perspective: allies or adversaries? In: GIDRON, Benjamin et al. Government and the third sector. San Francisco: Jossey-Bass Publishers, 1992, p. 1-30.

GODFRIN, Philippe e DEGOFFE, Michel. Droit administratif des biens. 8. ed. Paris: Dalloz, 2007.

GOYANES, Marcelo e COELHO, Daniele Maia Teixeira. O uso de naming rights no Brasil: breves considerações. Revista da ABPI - Associação Brasileira da Propriedade Intelectual, $n^{\circ} 110$, p. 55-60, jan./fev. 2011.

GRYNBAUM, Michael M.; WILENSKY-LANFORD, Ethan. M.T.A. Sells the Naming Rights to a Station, and Wants to Make More Deals. New York Times; 24.06.2009, p. 2332. Disponível em Ebscohost. Acesso em 22.09.2010.

HAAN, Perry' SHANK, Matt. Consumers' Perceptions of NFL Stadium Naming Rights. International Journal of Sports Marketing \& Sponsorship; mar/2004, vol. 5, ed. 4, p. 269281. Disponível em Ebscohost. Acesso em 22.09.2010.

HALTOM, Bill. The RC Cola/Moon Pie law offices of Dewey, Cheatem \& Howe: sports franchises and bowl games naming rights, Tennessee Bar Journal, jan/2007, v.43, p. 34. 
JUSTEN FILHO, Marçal. Curso de direito administrativo. 6. ed. rev. e atual., Belo Horizonte: Fórum, 2010.

A exploração econômica de bens públicos: cessão do direito à denominação. Revista de Direito Público da Economia - RDPE, Belo Horizonte, ano 8, n. 30, p. 175198, abr./jun. 2010.

KAY, Julie. A new level for naming rights, The National Law Journal, v. 31; ed.17, s./p., 22.12.2008.

KLARA, Robert. Cities for sale. MediaWeek; de 09.03.2009, vol. 19, ed. 10, seção especial, p. 6-8. Disponível em Ebscohost. Acesso em 22.09.2010.

LEITE, Eduardo de Oliveira. Monografia jurídica. 8. ed. rev., São Paulo: RT, 2008.

LÔBO, Paulo Luiz Netto. Comentários ao código civil. Coord. por Antônio Junqueira de Azevedo. São Paulo: Saraiva, 2003, v. 6, p. 293.

MAISASHVILI, Robin Lightner; SMITH, Nina, Fields of opportunities, publicado em Managing Intellectual Property, nov./2005, ed. 154, p. 33-35. Disponível em http://ezpprod1.hul.harvard.edu/login?url=http://search.ebscohost.com/login.aspx?direct=true $\& \mathrm{db}=\mathrm{b}$ th\&AN=18926742\&site=ehost-live \&scope $=$ site. Acesso em 02.09.2010.

MARCELLINO JÚNIOR, Julio Cesar. Princípio constitucional da eficiência administrativa: (des)encontros entre economia e direito. Florianópolis: Habitus, 2009, p. 186.

MARÉS, Chico. "Câmara cria limite para projeto de nome de rua em Curitiba", publicado no jornal Gazeta do Povo, Curitiba, Paraná, 27.04.2011. http://www.gazetadopovo.com.br/vidapublica/conteudo.phtml?tl=1\&id=1120042\&tit=Ca mara-cria-limite-para-projeto-de-nome-de-rua-em-Curitiba. Acesso em 02.05.2011.

MARGETON, Stephen G. Introduction to design for law and other academic libraries: reflection and change. 2. ed. William, S. Hein: New York, 2007. 
MARQUES NETO, Floriano de Azevedo. Bens públicos: função social e exploração econômica: o regime jurídico das utilidades públicas, Belo Horizonte: Fórum, 2009.

. Regulação estatal e interesses públicos. São Paulo: Malheiros, 2002.

MASAGÃO, Mário. Curso de direito administrativo. 5. ed. rev. e atual., São Paulo: Revista dos Tribunais, 1974.

MEDAUAR, Odete. Concessão de serviço público. São Paulo: Revista dos Tribunais, 1995.

Direito administrativo. 8. ed. São Paulo: Revista dos Tribunais, 2004.

MEIRELLES, Hely Lopes. Direito administrativo brasileiro. 5. ed., São Paulo: Revista dos Tribunais, 1977.

MENDES JÚNIOR, Onofre. Direito administrativo. 2. ed. rev. e aumentada. Belo Horizonte: Bernardo Álvares, 1961.

MINOW, Martha. "Symposium: public values in an era of privatization: public and private partnerships: accounting for the new religion", Harvard Law Review, The Harvard Law Review Association, março/2003, volume 116, p. 1.229-1.270.

MIRANDA, Pontes. Tratado de Direito Privado. 2. ed. Rio de Janeiro: Borsoi, 1956, v. XVI.

MONTESQUIEU. Do espírito das leis. Trad. Gabriela de Andrada Dias Barbosa, s/1: Ediouro, s/d.

MORAES, Alexandre. Direito constitucional. 12. ed., São Paulo: Atlas, 2002. Constituição do Brasil interpretada e legislação constitucional. 2. ed., São Paulo: Atlas, 2003.

MORAND-DEVILLER, Jacqueline. Cours droit administratif des biens, 5. ed., Paris: Montchrestien, 2007. 
MOREIRA, Egon Bockmann. Reflexões a propósito dos princípios da livre iniciativa e da função social, Revista de direito público da economia - RDPE, Belo Horizonte, ano 4, $\mathrm{n}^{\circ}$ 16, p. 27-42, out./dez. 2006.

MURRAY, Bobbi. Money for Nothing. The Nation, Set. 1/8, 2003, p. 25-28.

OVERTON, Reginald F., Naming Rights for High School Athletic Facilities. Coach \& Athletic Director; dezembro/2005, vol. 75, ed. 5, p. 74-76. Disponível em Ebscohost. Acesso em 22.09.2010.

PAESANI, Liliana Minardi. Comentários ao código civil. Coord. por Carlos Eduardo Nicoletti Camillo e outros. 2a . tir., São Paulo: Revista dos Tribunais, 2006.

PEREIRA, Caio Mário da Silva. Instituições de direito civil. 10. ed., Rio de Janeiro: Forense, v. III, 1997.

PINTO, Élida Graziane. Financiamento de direitos fundamentais: políticas públicas vinculadas, estabilização monetária e conflito distributivo no orçamento da União do pósplano real, Belo Horizonte: O Lutador, 2010.

REZENDE, Carla Andriele; RIFISKI, Maurício Gabriel. Naming rights: a nova tendência do marketing esportivo. Kyocera Arena - um estudo de caso. Curitiba. 2008. 114 fl. Monografia de graduação (Graduação em Comunicação Social com ênfase em Publicidade e Propaganda) - Faculdades Integradas do Brasil - Unibrasil.

RODRIGUES, Silvio. Direito civil. 34. ed. São Paulo: Saraiva, v. 1, 2003.

SANSEVERINO, Paulo de Tarso Vieira. Contratos nominados II. Estudos em homenagem ao Prof. Miguel Reale. Coord. por Miguel Reale e Judith Martins-Costa. São Paulo: Revista dos Tribunais, v. 4, 2005.

SCHMIDT, Paulo e SANTOS, José Luiz dos. Avaliação de ativos intangíveis. São Paulo: Atlas, 2002.

SERPA LOPES, Miguel Maria de. Curso de direito civil. 7. ed. rev. e atualiz. por José Serpa Santa Maria, Rio de janeiro: Freitas Bastos, 1989. 
SIMAS, Henrique de Carvalho. Manual elementar de direito administrativo. 3. ed. ampl., revista e atual., Rio de Janeiro: Liber Juris, 1987.

SUNDFELD, Carlos Ari. Fundamentos de direito público. 4. ed., 5. tiragem, São Paulo: Malheiros, 2004.

TÁCITO, Caio. Temas de direito público: estudos e pareceres. Rio de Janeiro: Renovar, 2002.

TEPEDINO, Gustavo. A Tutela da Personalidade no Ordenamento Civil-Constitucional Brasileiro. Temas de direito civil. 2. ed. rev. e atual. Rio de Janeiro-São Paulo: Renovar, 2001, p. 23-71.

THEODORO JÚNIOR, Humberto. Curso de direito processual civil. 25. ed. rev. e atualiz., Rio de Janeiro: Forense, v.1, 1998.

THOMSEN, Melinda. Naming rights. Georgetown: Finishing Line, 2008.

VILLELA SOUTO, Marcos Juruena. Direito administrativo contratual. Rio de Janeiro: Lumen Juris, 2004.

TRAORÉ, Seydou. Droit des propriétés publiques. Paris: Vuilbert, 2008.

VOIGT, Christian Maximilian. What's really in the package of a naming rights deal? Service mark rights and the naming rights of professional sports stadiums, publicado em Journal of Intellectual Property Law Association (11 J. Intell. Prop. L. 327), primavera/2004, p. 327. Acesso em 07.07.2011.

VON HOFFMAN, Constantine. Buying Up the Bleachers. Brandweek; 19/02/2007, vol. 48 ed. 8, p. 18-21. Disponível em Ebscohost. Acesso em 22.09.2010.

WALKER, Kim; JAMES, Steven. The name game. The Lawyer, 12/04/2010, GrãBretanha, vol. 24, ed. 15, p. 27. Disponível em Ebscohost. Acesso em 22.09.2010.

WEDEKIND, Jennifer. No-Name Naming Rights. Multinational Monitor; nov.-dez./2007, vol. 28 , ed. 5 , p. 55 . 
WEINBERGER, James D. Look before you leap into naming rights agreements. Managing Intellectual Property, out./2009, ed. 193. Disponível em Hollis. Acesso em 03.09.2010. 